Research Article

\title{
Constitutive Model of Rock Uniaxial Damage Based on Rock Strength Statistics
}

\author{
Ming Ji (D), ${ }^{1,2}$ Kai Chen, ${ }^{1}$ and Hong Jun Guo ${ }^{1}$ \\ ${ }^{1}$ Key Laboratory of Deep Coal Resource Mining, Ministry of Education of China, School of Mines, \\ China University of Mining \& Technology, Xuzhou 221116, China \\ ${ }^{2}$ School of Mining and Petroleum Engineering, Department of Civil and Environmental Engineering, \\ University of Alberta, Edmonton T6G 1H9, Canada \\ Correspondence should be addressed to Ming Ji; jiming@cumt.edu.cn
}

Received 19 July 2018; Accepted 5 September 2018; Published 21 October 2018

Guest Editor: Dengke Wang

Copyright ( 2018 Ming Ji et al. This is an open access article distributed under the Creative Commons Attribution License, which permits unrestricted use, distribution, and reproduction in any medium, provided the original work is properly cited.

\begin{abstract}
Based on the assumption that rock strength follows the log normal distribution statistically, this paper establishes a damage constitutive model of rock under uniaxial stress conditions in combination with the Mohr-Coulomb strength criterion and damage mechanical theory. Experiments were carried out to investigate the damage evolution process of rock material, which can be categorized into nondamaging, accelerated growth, constant-speed, similar growth, and speed-reducing growth stages. The evolution process had a good corresponding relationship with the rock stress-strain curves. Based on the statistical damage constitutive model proposed in this paper, a numerical fitting analysis was conducted on the uniaxial compression testing data of laboratory sand rock and on experimental data from other literature, in order to validate the rationality of the constitutive equation and the determination of its parameters and to analyze the effect of internal friction variables on damage variables and compression strength. The research outcomes presented in this paper can provide useful reference for the theory of rock mechanics and for rock engineering.
\end{abstract}

\section{Introduction}

Experiments have shown that rock is a type of complex medium. Under the application of external loading, rock presents a very complex nonlinear deformation, and the complex deformation results in complexity and uncertainty of rock engineering accordingly. Many investigators have tried to explain the relationship between the deformation of rock and external loading, i.e., the constitutive relationship of rock. The results of early research into rock mechanics include Hooke's law, Newton's law of viscosity, and Saint Venant's ideal plasticity law. The continuous recognition of progress in understanding the mechanical properties of rock has led investigators to propose a variety of constitutive models by means of a subsequent viscoelastic plastic theory of continuum mechanics, such as that put forward by Liu et al. [1]. Based on rheological theory, Liu et al. [1] proposed a mechanical constitutive model that can describe the rheology of fully saturated rock. Fu et al. [2] proposed an elastic-plastic constitutive model for soft sedimentary rock by using the conventional elastic-plastic constitutive model and considering the anisotropy and constraint-strain dependence of soft rock. Desai and Salami [3] proposed a constitutive model describing the deformation behavior of rock stress on the basis of the assumption that, in elasticplastic theory, rock behaviors such as hardening, volumetric variation, stress path, cohesion, tensile strength, and yield behavior vary with average pressure. Li et al. [4] carried out a research in the framework of the theory of plasticity, considered internal friction and cohesion as the variables of the plastic strain function, and proposed a hyperbolic hardening function for kinetic friction and a mixed parabolic exponential equation for kinetic cohesion. In combination with strength theory and the movement of the strength component, Li et al. [4] provided a yield function and proposed a mixed hardening/softening elastic-plastic constitutive model that can predict the stress-strain behavior of soft rock. 
Under the long-term application of external load and environmental conditions, many fine cracks and other defects are created inside rock. Owing to the existence of these defects, the mechanical properties of rock differ significantly from metal materials and polymers. The microstructure inside the rock material can cause the deterioration of the mechanical properties of the rock; therefore, the constitutive relationship of the rock material can be investigated from the point of view of damage mechanics. Damage mechanics assumes that the growth and confluence of various defects inside a material can result in the deterioration of its structure and accordingly, affect its mechanical properties.

Lemaitre [5] established a new elastic-plastic damage complex model on the basis of the maximum loss principle, achieving strong coupling between plasticity and damage. Cerrolaza and Garcia [6] established a nonlinear mechanical model to explain the stress-strain relationship of damaged rock during excavation on the basis of damage mechanical theory and in combination with the boundary method. By combining plasticity mechanics and damage mechanics, Unteregger et al. [7] created a constitutive model that could describe the nonlinear mechanical behaviors (including irreversible deformation, strain hardening, and strain softening) and bear complex three-dimensional stress for various types of rocks. Based on the assumption that the crack growth of rock during the postpeak period is the process of cohesive instability and making use of the nonassociated plastic potential function of rock plastic deformation and expansion derived from the dilation angle, Pourhosseini and Shabanimashcool [8] developed a damage constitutive model to describe the nonlinear behaviors of intact rock under static load (including prepeaking elastic behaviors and postpeaking strain-softening behaviors). Zhou and Zhu [9] investigated the plastic friction and the deformation mechanisms of plastic holes on the basis of irreversible thermodynamic theory and damage mechanical theory. They established a plastic friction yield criterion through a parabolic function that included volumetric deformation effects. They then proposed a plastic hole yield criterion by making use of Gurson's criterion and a friction yield model to determine the matrix deformation of porous materials. Combining these two criteria, they developed an elasticplastic damage constitutive model with two yield surfaces. Based on continuum damage mechanics theory and from the microscopic viewpoint, Shao and Rudnicki [10] created a microcontinuum damage model to describe the brittle rock solid material that is mainly dominated by compression.

Statistical physics theory has been widely used in the evolution and development of microscopic damage mechanics [11-13] and in the establishment of many constitutive models [14-16] that consider rock damage statistics. Guang [17] pointed out that due to the heterogeneity of rock mechanical properties, probability statistical analysis can be applied to analyze rock strength. Based on damage mechanics and probability statistical analysis of rock strength, Guang devised the concept of rock damage and created the constitutive model for it. Based on the theory of damage mechanics and statistical strength theory, Li et al. [18] established a damage statistical constitutive model to analyze the softening deformation of rock strain. Budiansky [19] pointed out that microscopic damage mechanics used quantum and statistical mechanics to determine the impact of damage on microscopic structures and then inferred their macro-mechanical effects. Meanwhile, microscopic damage mechanics illuminated the quantitative relationship [20] between microscopic damage structure and mechanical parameters.

In the constitutive models that consider the statistics of damage evolution, the investigators defined the types of various microelement strength distributions, including Weibull distribution [21-24], normal distribution [25], power function distribution [26], and so on. To define the microelement damage criterion, they made use of the Mohr-Coulomb (M-C) and Drucker-Prager (D-P) criteria. Based on the fact that rock strength microelements follow a random distribution, and on the $\mathrm{M}-\mathrm{C}$ rock damage criterion, we have assumed that the strength distribution of microelements complies with a log normal distribution function, studied the statistical damage evolution of microelements in the loading process of rock, and established a damage constitutive equation of rock uniaxial damage. Thus, our research provides references for rock mechanics research and engineering.

\section{Establishment of Statistical Damage Constitutive Model}

It is assumed that $N$ is the total microelement number of rock and that $N_{\mathrm{d}}$ is the microelement number of damaged rock under a certain load, and then $D$ is defined as the statistical damage variable, i.e.,

$$
D=\frac{N_{\mathrm{d}}}{N}
$$

When the internal microelement stress $\sigma_{\mathrm{s}}$ of rock reaches its strength $F$, the microelement fails. Assuming that the microelement strength $F$ follows a certain probability distribution, the number of failed microelements at any stress level interval $\left[\sigma_{\mathrm{s}}, \sigma_{\mathrm{s}}+d \sigma_{\mathrm{s}}\right]$ can then be determined by

$$
d N_{\mathrm{d}}=N p\left(\sigma_{\mathrm{s}}\right) d \sigma_{\mathrm{s}}
$$

where $p$ represents the density function of the probability distribution for the microelement strength $F$.

When loading reaches a certain stress level $\sigma_{s}$, the number of failed microelements is

$$
N_{\mathrm{d}}=\int_{0}^{\sigma_{\mathrm{s}}} N p(x) d x=N p\left(\sigma_{\mathrm{s}}\right),
$$

where $p$ represents the distribution function of the probability distribution for the microelement strength $F$.

From Equations (1) and (3), the following equation can be derived:

$$
D=p\left(\sigma_{\mathrm{s}}\right)
$$

which, in turn, can be used to derive the statistical damage evolution equation. For any probability distribution, with 
the increase of stress level $\sigma_{\mathrm{s}}$, the distribution function value varies from 0 to 1 . The value of $D$ reflects the extent of internal damage of the materials: when $D=0$, it indicates intact material without damage, and when $D=1$, it indicates completely failed material.

The stress level $\sigma_{\mathrm{s}}$ can be represented by the common $\mathrm{M}-\mathrm{C}$ criterion as

$$
\sigma_{\mathrm{s}}=\sigma_{1}^{*}-\sigma_{3}^{*}-\left(\sigma_{1}^{*}+\sigma_{3}^{*}\right) \sin \varphi=c \cos \varphi,
$$

where $\sigma_{1}^{*}, \sigma_{2}^{*}$, and $\sigma_{3}^{*}$ denote the effective principal stresses and $\sigma_{1}^{*} \geq \sigma_{2}^{*} \geq \sigma_{3}^{*}$ and $c$ and $\varphi$ denote the cohesion and internal friction angle of the material, respectively.

According to Hooke's law, the principal strain can be expressed by

$$
\varepsilon_{i}=\frac{1}{E}\left[(1+\mu) \sigma_{i}^{*}-\mu\left(\sigma_{1}^{*}+\sigma_{2}^{*}+\sigma_{3}^{*}\right)\right], \quad i=1,2,3,
$$

where $\sigma_{1}^{*}$ is the effective principal stress, $E$ is the Young modulus, and $\mu$ is the Poisson ratio.

We next introduce the strain equivalent hypothesis $[27,28]$ in the following equation, where $\sigma_{i}$ denotes the apparent stress:

$$
\sigma_{i}^{*}=\frac{\sigma_{i}}{1-D}, \quad i=1,2,3 .
$$

Substituting Equation (7) into Equation (6), we obtain

$$
D=1-\frac{1}{E \varepsilon_{i}}\left[(1+\mu) \sigma_{i}-\mu\left(\sigma_{1}+\sigma_{2}+\sigma_{3}\right)\right] .
$$

Substituting Equation (8) into Equation (4), the general form of the statistical damage constitutive equation can be expressed as

$$
P\left(\sigma_{\mathrm{s}}\right)=1-\frac{1}{E \varepsilon_{i}}\left[(1+\mu) \sigma_{i}-\mu\left(\sigma_{1}+\sigma_{2}+\sigma_{3}\right)\right] .
$$

For uniaxial compression experiments, Equation (8) can be written as

$$
\sigma_{1}=E \varepsilon_{1}(1-D),
$$

which can be substituted into Equation (7) to obtain

$$
\sigma_{1}^{*}=E \varepsilon_{1} .
$$

According to Equations (10) and (11), the apparent stress $\sigma_{1}$ and axial strain can be used to calculate the damage variable $D$ and effective stress $\sigma_{1}^{*}$.

Equation (9) can be directly utilized to achieve the general form of the constitutive model of uniaxial testing statistical damage as

$$
\sigma=E \varepsilon\left(1-P\left(\sigma_{s}\right)\right),
$$

where $\sigma$ and $\varepsilon$ are the stress and strain, respectively, for rock specimens under uniaxial compression.

Considering the situation of uniaxial stress and substituting Equation (5) into Equation (12), we obtain

$$
\sigma=E \varepsilon\{1-P[(1-\sin \varphi) E \varepsilon]\} .
$$

Assuming that the rock strength follows a log normal distribution, its probability density function is

$$
P\left(\sigma_{\mathrm{s}}\right)=\Phi\left[\frac{\ln \left(\sigma_{\mathrm{s}} / \sigma_{\mathrm{s}}^{0}\right)}{\eta}\right]=\Phi\left[a \ln \left(\sigma_{\mathrm{s}}\right)+b\right],
$$

where $\sigma_{s}^{0}$ and $\eta$ are distribution parameters, $a=1 / \eta$ and $=-\left(\ln \sigma_{\mathrm{s}}^{0}\right) / \eta$. $\Phi$ is the standard normal distribution function, defined by

$$
\left\{\begin{array}{l}
\Phi(x)=\int_{-\infty}^{x} \varnothing\left(\sigma_{s}\right) d \sigma_{s}, \\
\varnothing(x)=\frac{1}{\sqrt{2 \pi}} \exp \left(-\frac{x^{2}}{2}\right) .
\end{array}\right.
$$

The two statistical parameters in Equation (15) can be determined using the linear fitting [28], peak value [29], and inversion analysis methods [25, 30], among others. We utilized the peak value characteristics of the stress-strain curves and solved these parameters using the extreme value method.

Substituting Equation (14) into Equation (12), we obtain the constitutive equations (16) and (17) of the damage evolution and statistical damage based on the $\mathrm{M}-\mathrm{C}$ criterion, respectively:

$$
\begin{aligned}
D & =\Phi\left(a \ln \varepsilon+b_{1}\right), \\
\sigma & =E \varepsilon\left[1-\Phi\left(a \ln \varepsilon+b_{1}\right)\right],
\end{aligned}
$$

where $b_{1}=a \ln [(1-\sin \varphi) E]+b$.

Considering the full stress-strain curve of uniaxial compression and defining $\varepsilon_{1}$ and $\sigma_{1}$ as the strain and stress, respectively, at the peak values of the full stress-strain curves, we get $\varepsilon=\varepsilon_{1}, \sigma=\sigma_{2}$, and $d \sigma_{1} / d \varepsilon_{1}=0$ :

$$
\left\{\begin{array}{l}
\sigma_{1}=E \varepsilon_{1}\left[1-\Phi\left(a \ln \varepsilon_{1}+b_{1}\right)\right], \\
\sigma_{1}=a E \varepsilon_{1} \varnothing\left(-a \ln \varepsilon_{1}-b_{1}\right) .
\end{array}\right.
$$

Equation (18) can be used to solve the parameters $a$ and $b_{1}$ in Equation (17).

\section{Experimental Validation of Models}

To validate the accuracy of the above constitutive model, uniaxial compression tests were conducted in the laboratory for three sand rock specimens as shown in Figure 1. The testing apparatus included the electrohydraulic, servocontrolled MTS Model 815.02 Rock Mechanics Test System (MTS Systems Corp., USA), which was loaded by displacement control with a loading rate of $0.002 \mathrm{~mm} / \mathrm{s}$.

Based on the damage equations presented in this paper, the evolution regularity chart for the three rock specimens in the loading process were prepared as shown in Figures 2(a)-2(c). The damage evolution of the rock during the loading process can be divided into four stages: (1) a nondamaged stage at the beginning of loading (OE), which responded to the compression and linear elastic stage in the stress-strain curve of the rock; (2) an accelerated growth stage (EF), which responded to the prepeak yield stage in the stress-strain curve of the rock; (3) a constant-speed-similar growth stage (FG), which responded to the postpeak stage in the stress-strain curve of the rock; and 


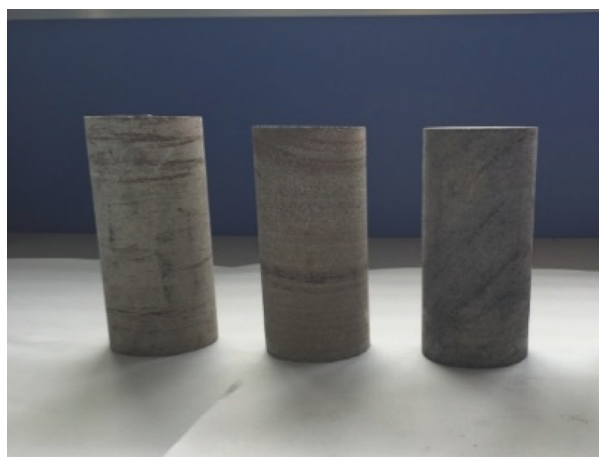

FIgURE 1: Specimen of sand rock.

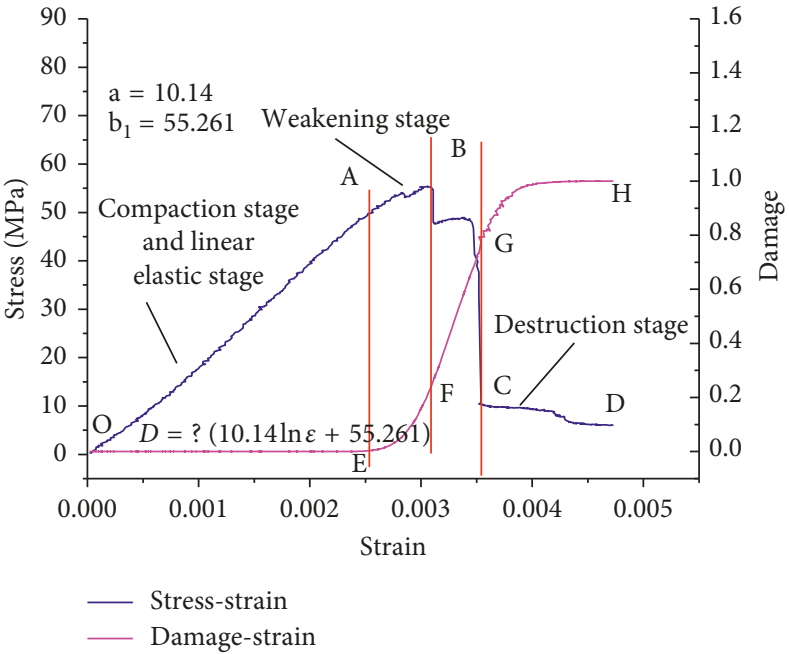

(a)

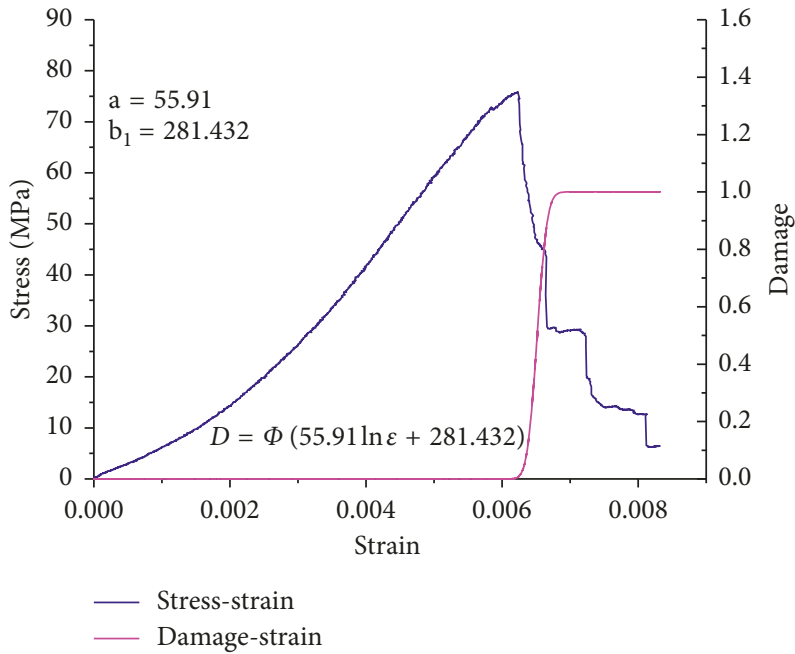

(b)

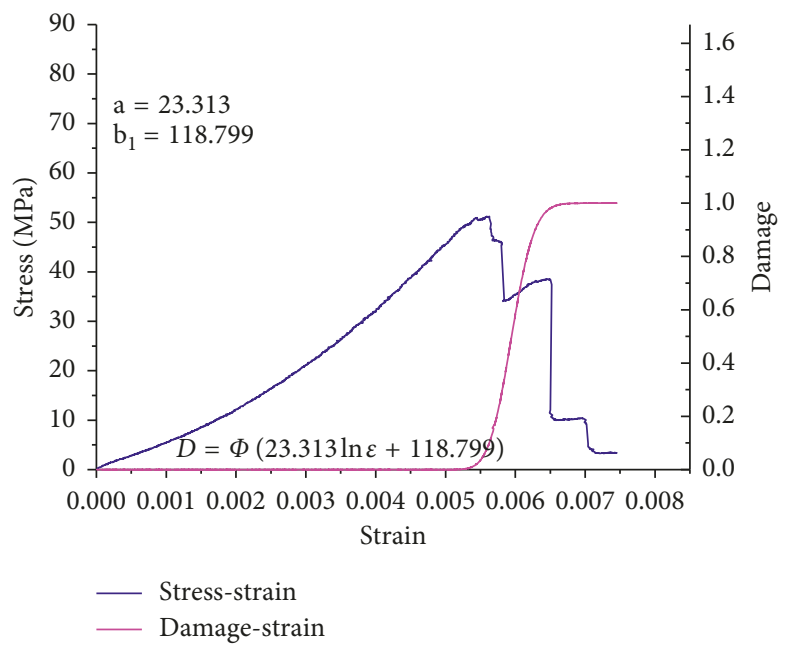

(c)

Figure 2: Evolution of damage variable. (a) Sample no. 1. (b) Sample no. 2. (c) Sample no. 3.

(4) a speed-reducing growth stage $(\mathrm{GH})$, which responded to the residual stress stage in the stress-strain curve of the rock.

The theoretical and experimental data curves were individually prepared as shown in Figures 3(a)-3(c) based on the damage constitutive model presented in this paper, and the correlation coefficients between modeling data and lab data are $0.9995,0.8095$, and 0.7867 . The statistical constitutive equation matched the real uniaxial compression testing curves of the rock well. This latter observation indicated that the proposed constitutive equation was able to represent the elastic, yield, and softening stages of the uniaxial stress-strain curve of the rock, and that the 


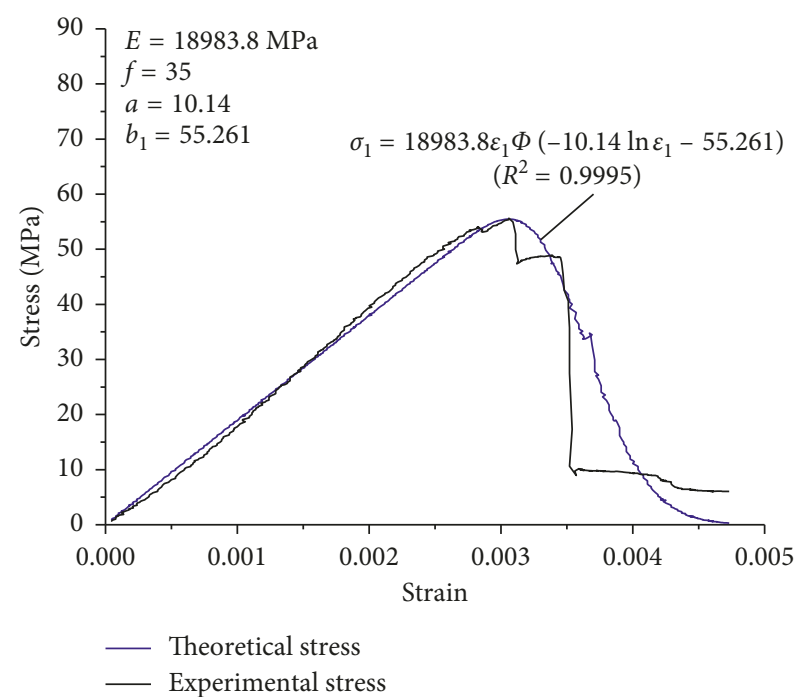

(a)

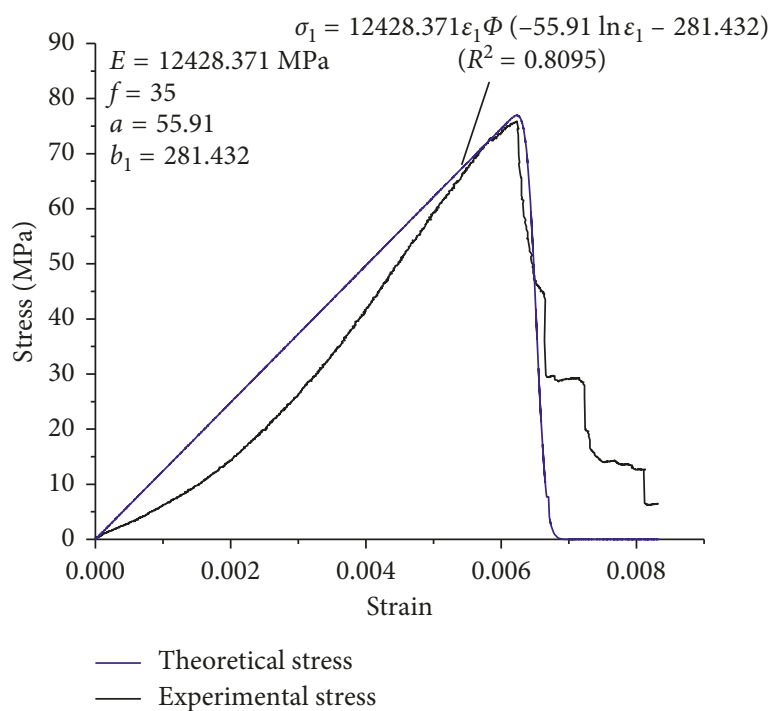

(b)

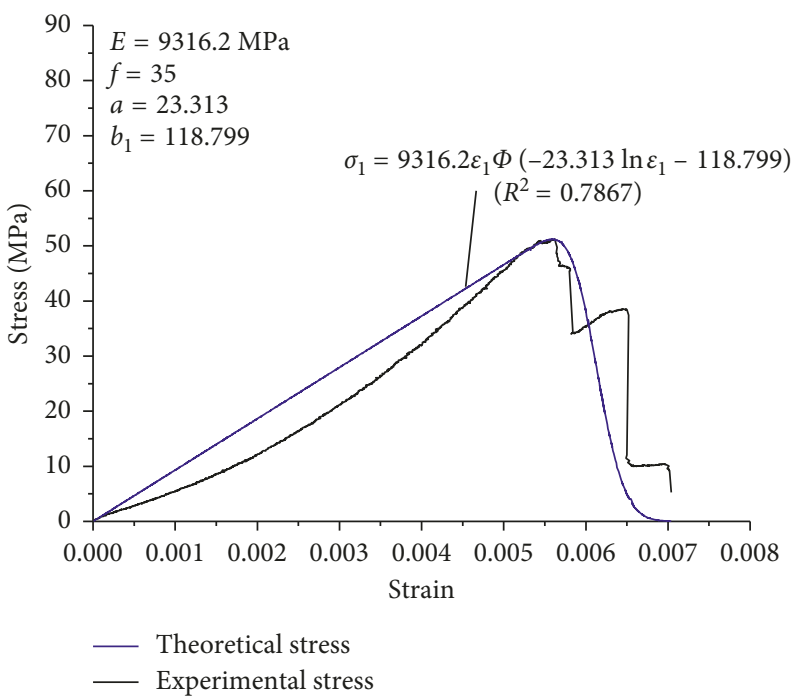

(c)

Figure 3: Comparison of theoretical results and experimental data. (a) Sample no. 1. (b) Sample no. 2. (c) Sample no. 3.

constitutive model was able to describe the strength and deformation characteristics of the uniaxial stress-strain curve of the rock.

Ji et al. [31] also proposed a constitutive model for two kinds of rocks, but the fitting results were not good. Ji et al. concluded that the constitutive relationship can only partially represent the loading characteristics of rock. Making use of the data presented in that paper and combining it with the constitutive relationship derived in this research, the theoretical curve and experimental data were prepared for validation and results comparison. As shown in Figures $4(a)-4(c)$, the fitting correlation coefficient between modeling data and lab data with the model of this paper is the highest one, so the rock constitutive equation in this paper provided a better description of the rock constitutive relationship than that in Ji et al.'s previous paper.

\section{Impact of Parameters on Constitutive Equations}

Using the uniaxial compression and shear testing data of sand rock as an example, the related parameters were $\varphi=35^{\circ}, a=10.14$, and $b=-33.34$. When the parameters $a$ and $b$ were constant, the internal friction angle $\varphi$ value was changed to achieve the stress-strain and damage-strain curves as shown in Figures 5 and 6, respectively.

From the viewpoint of the stress-strain relationship, the internal friction angle $\varphi$ reflects the uniaxial compression strength of rock, but it does not change the form of the stress-strain curve. The higher the internal friction angle, the higher the peak strength; on the other hand, the smaller the internal friction angle, the lower the peak strength. This observation is consistent with the characteristic represented by the uniaxial compression strength 


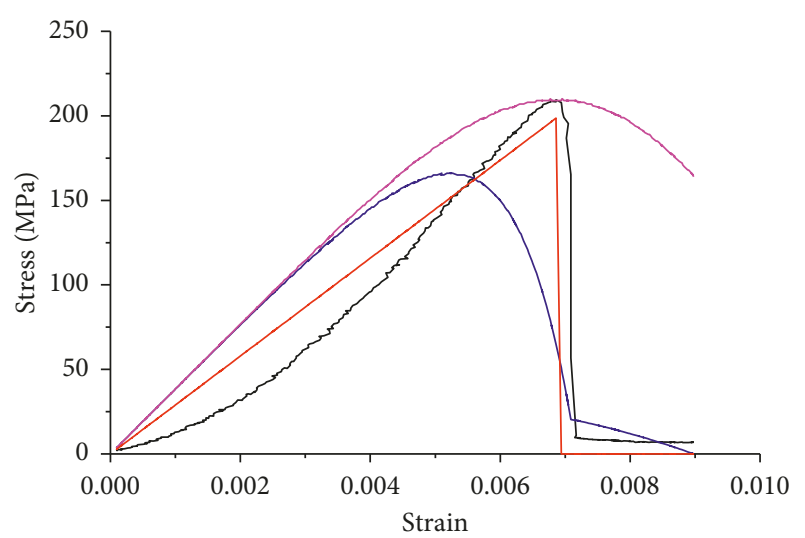

Experimental result in paper by Ji et al. [31]
Theoretical curve 1 in paper by Ji et al. [31] $\left(R^{2}=0.5548\right)$
Theoretical curve 2 in paper by Ji et al. [31] $\left(R^{2}=0.3046\right)$
Theoretical curve in this paper $\left(R^{2}=0.7913\right)$

(a)

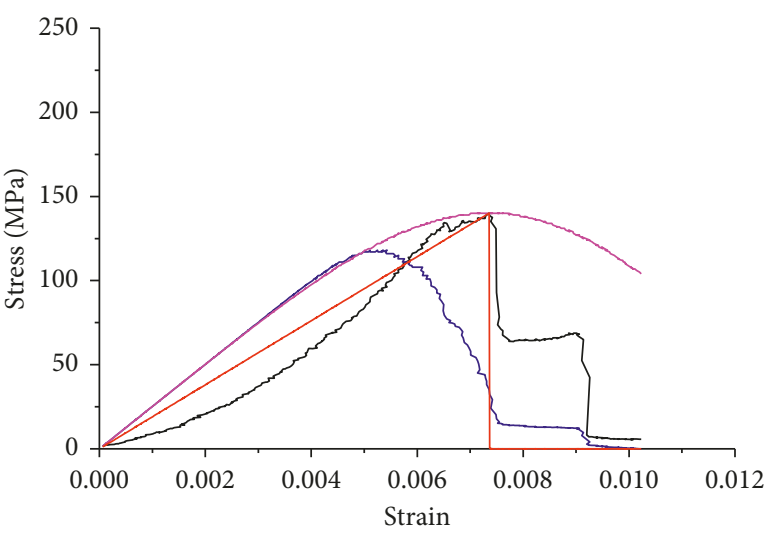

_ Experimental result in paper by Ji et al. [31]

- Theoretical curve 1 in paper by Ji et al. [31] $\left(R^{2}=0.2819\right)$

- Theoretical curve 2 in paper by Ji et al. [31] $\left(R^{2}=0.5427\right)$

Theoretical curve in this paper $\left(R^{2}=0.6956\right)$

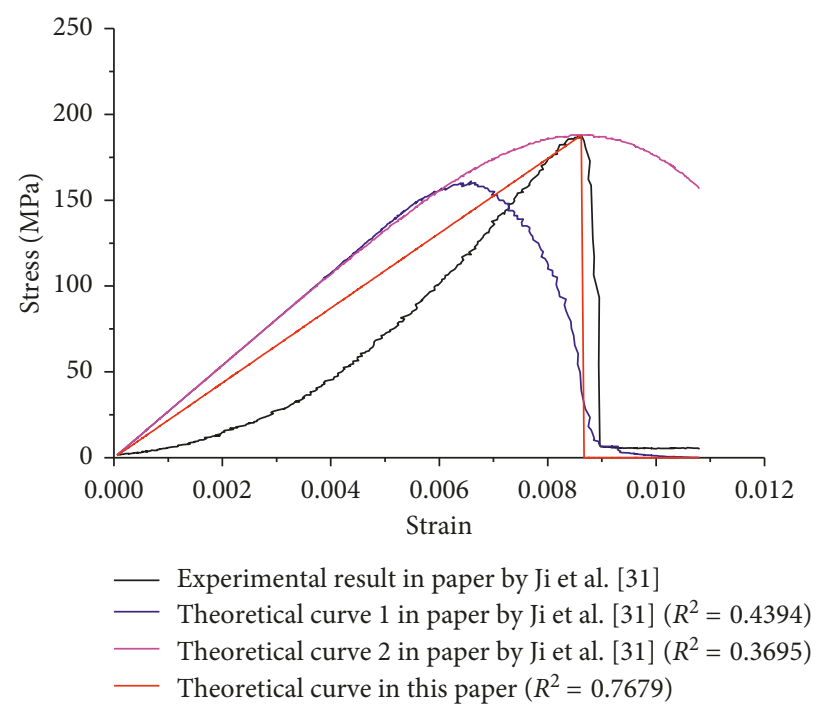

(c)

Figure 4: Curves of the theoretical fitting from Ji et al. [31]. (a) Sample no. 1. (b) Sample no. 2. (c) Sample no. 3.

Equation (19). Under the conditions of Coulomb's criteria [32]:

$$
\sigma_{\mathrm{c}}=2 c \sqrt{\frac{1+\sin \varphi}{1-\sin \varphi}},
$$

where $\sigma_{\mathrm{c}}$ represents the peak value of the strength in the uniaxial stress-strain curve and $c$ is the inhesion of the rock material.

From Figure 6, it is observed that with increasing internal friction angle $\varphi$, the deformation of rock from nondamaged status to accelerated damage status increased and the evolution process of rock to reach complete damage status was delayed. This means that the compression durability of rock increased with a higher internal friction angle. Under the condition of an identical damage value, the rock strain accordingly increased with increasing internal friction angle $\varphi$. Under the identical strain condition, the damage value of rock decreased with the increasing internal friction angle.

\section{Conclusions}

In this paper, the general form of the rock statistical damage constitutive model is inferred under the uniaxial stress condition, and the model parameters are determined by using uniaxial compression testing. In addition, the reliability of the proposed constitutive model is checked through analysis of testing data and concluded the following:

(1) On the basis of strength theory and the random distribution characteristics of rock, in this research, we established a damage evolution equation based on statistics

(2) Based on the M-C criterion, we established a statistical damage constitutive model, and identified that 


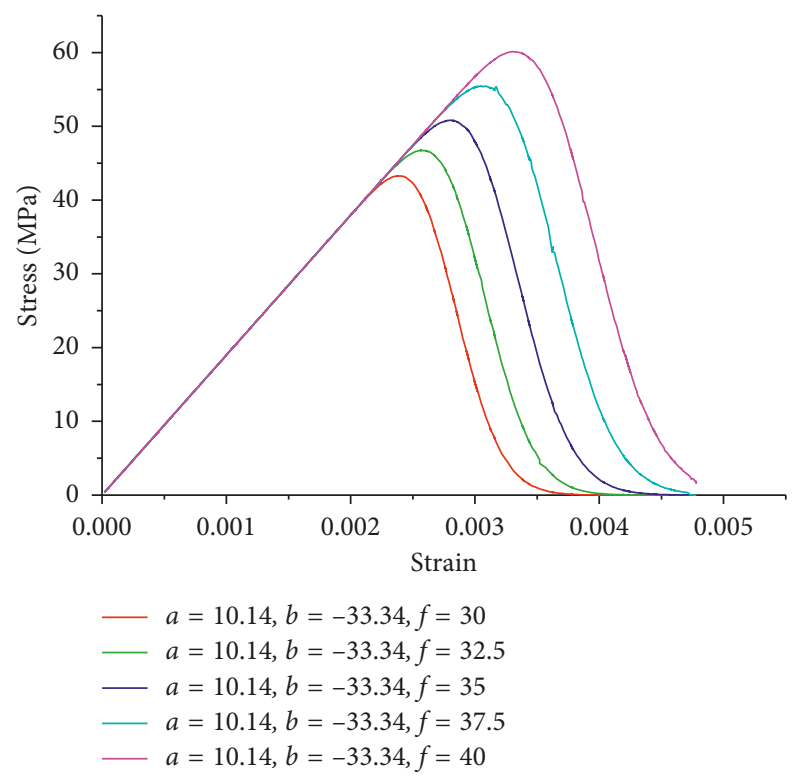

FIgURE 5: Impact of internal friction angle $\varphi$ on the constitutive model.

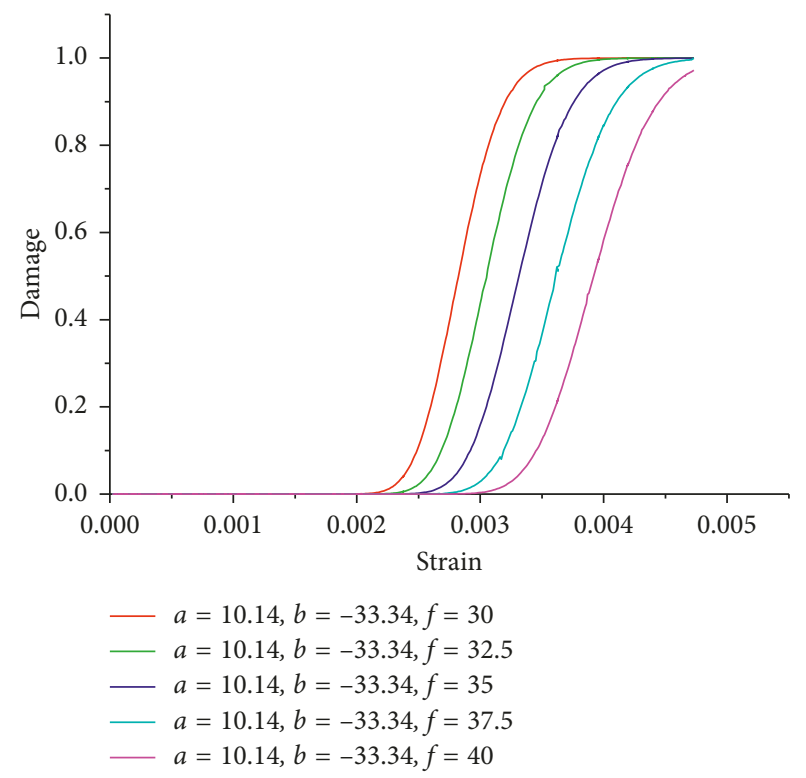

FIGURE 6: Impact of internal friction angle $\varphi$ on damage evolution.

the model was able to describe the mechanical behaviors of rock under uniaxial compression testing

(3) The variation of the internal friction angle had a certain impact on the uniaxial compression strength and damage evolution and reflected the compression durability of rock

\section{Data Availability}

All of the data supporting the conclusions of the study are available in the article and the authors are willing to share the data underlying the findings of the article.

\section{Disclosure}

The abstract of this paper had been accepted by the conference of GeoEdmonton 2018, but the full paper has not been submitted to the conference.

\section{Conflicts of Interest}

The authors declare that there are no conflicts of interest regarding the publication of this paper.

\section{Acknowledgments}

This paper was supported by Priority Academic Program Development of Jiangsu Higher Education Institutions and the Fundamental Research Funds for the Central Universities (2017XKQY044).

\section{References}

[1] L. Liu, G. M. Wang, J. H. Chen, and S. Yang, "Creep experiment and rheological model of deep saturated rock," Transactions of Nonferrous Metals Society of China, vol. 23, no. 2, pp. 478-483, 2013.

[2] Y. Fu, M. Iwata, W. Ding, F. Zhang, and Y. Yashima, "An elastoplastic model for soft sedimentary rock considering inherent anisotropy and confining-stress dependency," Soils and Foundations, vol. 52, no. 4, pp. 575-589, 2012.

[3] C. S. Desai and M. R. Salami, "A constitutive model and associated testing for soft rock," International Journal of Rock Mechanics and Mining Sciences \& Geomechanics Abstracts, vol. 24, no. 5, pp. 299-307, 1987.

[4] H. Z. Li, G. D. Xiong, and G. P. Zhao, "An elasto-plastic constitutive model for soft rock considering mobilization of strength," Transactions of Nonferrous Metals Society of China, vol. 26, no. 3, pp. 822-834, 2016.

[5] J. Lemaitre, "A continuous damage mechanics model for ductile materials," Journal of Engineering Materials and Technology, vol. 107, no. 1, pp. 83-89, 1985.

[6] M. Cerrolaza and R. Garcia, "Boundary elements and damage mechanics to analyze excavations in rock mass," Engineering Analysis with Boundary Elements, vol. 20, no. 1, pp. 1-16, 1997.

[7] D. Unteregger, B. Fuchs, and G. Hofstetter, "A damage plasticity model for different types of intact rock," International Journal of Rock Mechanics and Mining Sciences, vol. 80, pp. 402-411, 2015.

[8] O. Pourhosseini and M. Shabanimashcool, "Development of an elasto-plastic constitutive model for intact rocks," International Journal of Rock Mechanics and Mining Sciences, vol. 66, pp. 1-12, 2014.

[9] C. Y. Zhou and F. X. Zhu, "An elasto-plastic damage constitutive model with double yield surfaces for saturated soft rock," International Journal of Rock Mechanics and Mining Sciences, vol. 47, no. 3, pp. 385-395, 2010.

[10] J. F. Shao and J. W. Rudnicki, "A microcrack-based continuous damage model for brittle geomaterials," Mechanics of Materials, vol. 32, no. 10, pp. 607-619, 2000.

[11] W. Weibull, "A Statistical theory of the strength of materials," Royal Swedish of Institute for Engineering Research, vol. 151, no. 15, pp. 1-45, 1939.

[12] M. Sahimi and S. Arbabi, "Mechanics of disordered solids," Physical Review B, vol. 47, no. 2, pp. 713-722, 1993. 
[13] Y. Q. Yang, "Damage mechanics analysis of rock strength," Chinese Journal of Rock Mechanics and Engineering, vol. 18, no. 1, pp. 23-27, 1999.

[14] J. Marigo, "Modelling of brittle and fatigue damage for elastic material by growth of microvoids," Engineering Fracture Mechanics, vol. 21, no. 4, pp. 861-874, 1985.

[15] D. Krajcinovc, "Constitutive equation for damaging materials," Journal of Applied Mechanics, vol. 50, no. 2, pp. 355360, 1983.

[16] J. C. Simo and J. W. Ju, "Strain-and stress-based continuum damage models. Part I: formulation, part II: computational aspects," International Journal of Solid Structures, vol. 23, no. 3, pp. 821-869, 1988.

[17] Y. H. Guang, "A few questions of statistics of rock mechanical parameters," Red River, vol. 14, no. 1, pp. 37-41, 1995.

[18] X. Li, W. G. Cao, and Y. H. Su, "A statistical damage constitutive model for softening behavior of rocks," Engineering Geology, vol. 143-144, pp. 1-17, 2012.

[19] B. Budiansky, Micromechanics Advances and Trends in Structural and Solid Mechanics, A. K. Noor and J. M. Housner, Eds., Pergamon Press, Oxford, UK, 1983.

[20] Z. P. Bazant and J. Ozbolt, "Nonlocal micro plane model for fracture damage and size effect in structures," Journal of Engineering Mechanics, vol. 116, no. 11, pp. 2485-2505, 1990.

[21] A. Benallal, R. Billardon, and J. Lemaitre, "Failure analysis of structures by continuum damage mechanics," Fracture, vol. 84, pp. 3669-3676, 1984

[22] B. Basu, D. Tiwari, D. Kundu, and R. Prasad, "Is Weibull distribution the most appropriate statistical strength distribution for brittle materials?," Ceramics International, vol. 35, no. 1, pp. 237-246, 2009.

[23] Z. L. Wang, Y. C. Li, and J. G. Wang, "A damage-softening statistical constitutive model considering rock residual strength," Computers \& Geosciences, vol. 33, no. 1, pp. 1-9, 2007.

[24] J. G. Wang, S. Anand, and F. J. Ye, "A statistical damageconstitutive model of brittle rocks based on Weibull distribution," in Proceedings of the First Southern Hemisphere International Rock Mechanics Symposium (SHIRMS), Y. Potvin, J. Carter, A. Dyskin, and R. Jeffrey, Eds., pp. 121-134, Perth, Australia, September 2008.

[25] W. G. Cao, P. Li, and M. H. Zhao, "On statistical damage constitutive model and its parameters for rock based on normal distribution," Chinese Hydrogeology \& Engineering Geology, vol. 32, no. 3, pp. 11-14, 2008.

[26] C. Liu, L. Yang, and W. Cao, "A statistical damage softening constitutive model for rock and back analysis of its parameters," Chinese Journal of Underground Space and Engineering, vol. 3, no. 3, pp. 453-457, 2007.

[27] M. Zhang, F. Wang, and Q. Yang, "Statistical damage constitutive model of rock based on triaxial compression test," Chinese Journal of Geotechnical Engineering, vol. 35, no. 11, pp. 1965-1971, 2013.

[28] F. Wang, The Study on Statistical Damage Constitutive Model of Rock Based on Triaxial Compression Experiment, Tsinghua University Press, Beijing, China, 2013.

[29] H. Zhao, The Study on Statistical Damage Simulation Method of Rock Deformation Characteristics and the Whole Process of Deformation, Hunan University Press, Changsha, China, 2011.

[30] W. G. Cao, H. Zhang, Y. J. Zhang, and L. Zhang, "Strain softening and hardening damage constitutive model for rock considering effect of volume change and its parameters determination method," Chinese Journal of Rock and Soil Mechanics, vol. 32, no. 3, 2011.
[31] M. Ji, Y. D. Zhang, W. P. Liu, and L. Chen, "Damage evolution law based on acoustic emission and Weibull distribution of granite under uniaxial stress," Acta Geodynamica et Geomaterialia, vol. 3, no. 175, pp. 269-277, 2014.

[32] M. F. Cai, M. C. He, and Y. D. Liu, Rock Mechanics and Engineering, Science Press, Beijing, China, 2002. 


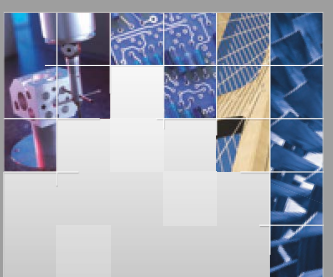

\section{Enfincering}
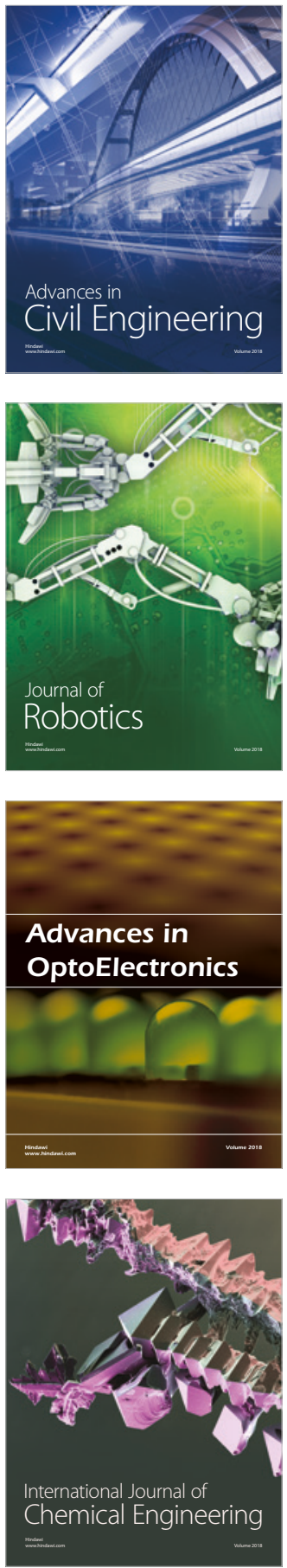

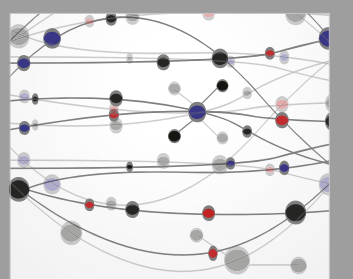

\section{Rotating \\ Machinery}

The Scientific World Journal

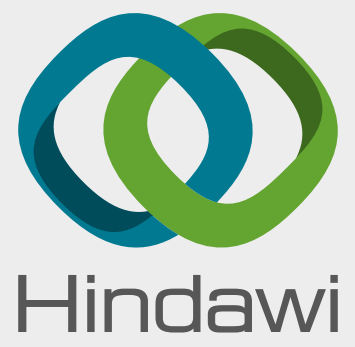

Submit your manuscripts at

www.hindawi.com
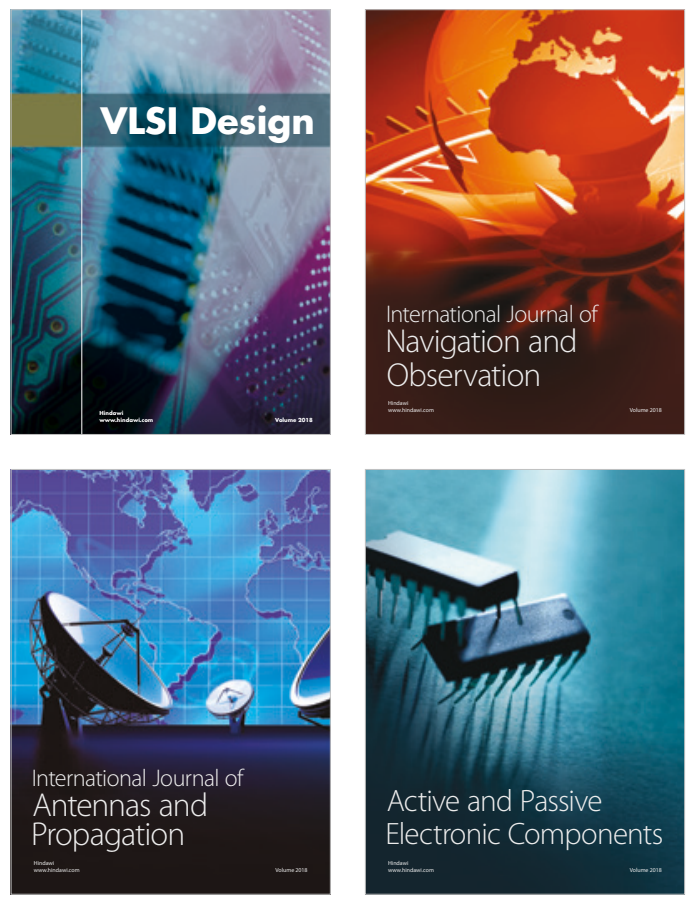
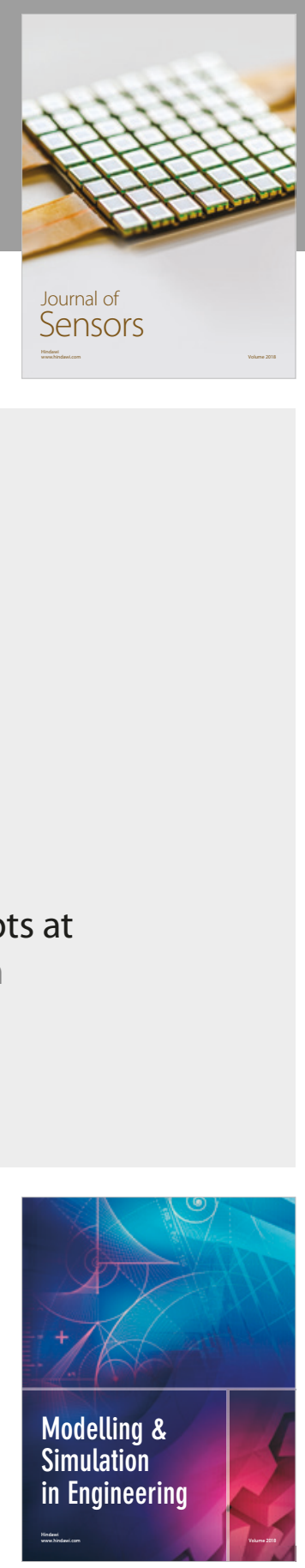

\section{Advances \\ Multimedia}
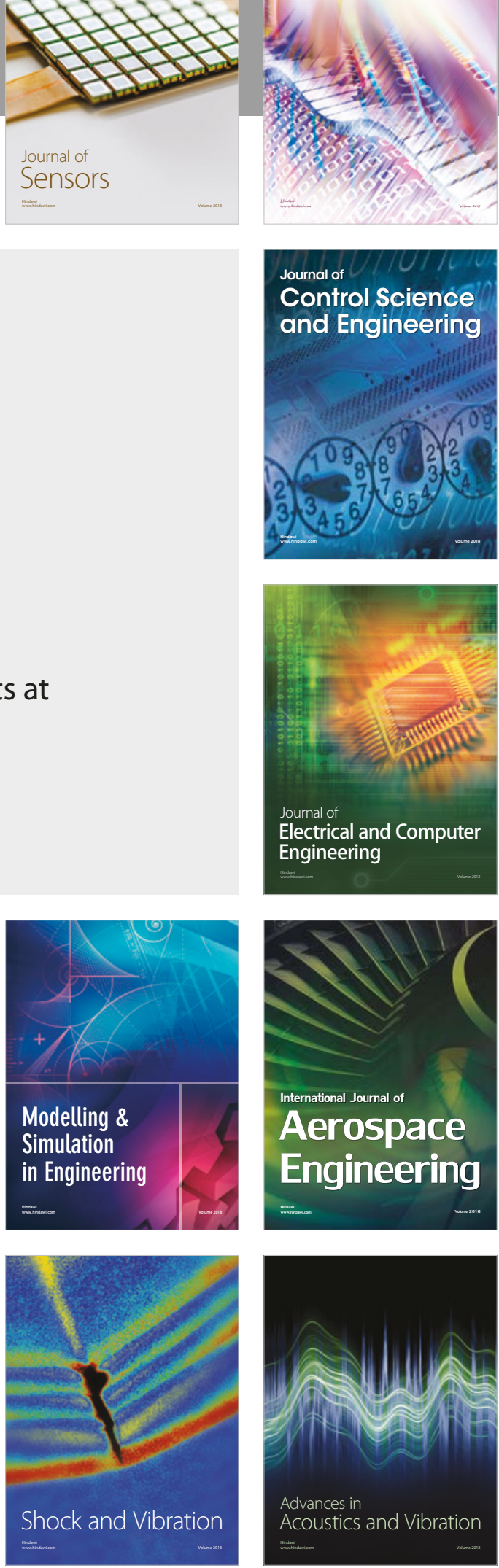